\title{
Association of Younger Age With Poor Glycemic and Cholesterol Control in Asians With Type 2 Diabetes Mellitus in Singapore
}

\author{
Matthias Paul Han Sim Toh ${ }^{\mathrm{a}, \mathrm{c}}$, Christine Xia Wu ${ }^{\mathrm{a}}$, Helen Soh Sum Leong ${ }^{\mathrm{b}}$
}

\begin{abstract}
Background: The prevalence of type 2 diabetes mellitus (T2DM) in children and adolescents is increasing in both poor and rich countries. Epidemiologic studies have reported significant and continuous associations between $\mathrm{HbA} 1 \mathrm{c}$ level and diabetes-related vascular complications. Younger adults with early exposure to hyperglycemia are at high risk for end-organ damage. Few studies have reported the relationship of age to glycemic control in patients with T2DM world-wide and little comparison among young adults and elderly patients especially in the Asian population. This study investigates the relationship of age and glycemic control in Asian patients with T2DM attending primary care clinics in Singapore.
\end{abstract}

Methods: We included T2DM patients who had at least 2 visits to the public-sector primary care clinic for diabetes treatment in 2009. Demographic characteristics, medical records and laboratory results were extracted from the enterprise-wide chronic disease registry. The mean HbA1c, blood pressure and LDL-cholesterol were trended by age. Multivariate logistic regression was used to identify the factors predicting "poor" glycemic control.

Results: There were 58,057 T2DM patients and both the mean HbA1c and LDL-cholesterol were lower among elderly than adult patients. Mean $\mathrm{HbAlc}$ was $8.08 \pm 1.62 \%$ for patients $<45$ years old and $6.86 \pm 0.99 \%$ for patients $85+$ years old. Mean LDL-cholesterol

Manuscript accepted for publication April 7, 2011

${ }^{a}$ Health Services and Outcomes Research, National Healthcare Group Singapore

${ }^{\mathrm{b}}$ Clinical Services, National Healthcare Group Polyclinics, Singapore

${ }^{\mathrm{c} C}$ Corresponding author: Matthias Toh, Health Services and Outcomes

Research, National Healthcare Group, 6 Commonwealth Lane,

\#04-01/02 GMTI Building, Singapore 149547.

Email: matthias_toh@nhg.com.sg

doi:10.4021/jem13e levels were $2.84 \pm 0.81$ and $2.55 \pm 0.73 \mathrm{mmol} / \mathrm{L}$ for the respective age groups. The Malay and Indian groups had significantly poorer glycemic control compared to the Chinese, AdjOR 1.65 (95\% CI: 1.54 - 1.77) and 1.50 (95\% CI: 1.40 - 1.61) respectively. Other significant predictors of poor glycemic control included the male gender, presence of maculopathy or retinopathy, peripheral vascular disease, coronary heart disease, heart failure, and being on insulin therapy (AdjOR 8.00; 95\% CI: 7.54 - 8.48). Patients with poor LDL-c $(4.1+\mathrm{mmol} / \mathrm{L})$ were 4.2 times more likely to have poor glycemic control $(95 \%$ CI: 3.78 - 4.66) while those with Grade 2 hypertension were 1.5 times (95\% CI: 1.35 - 1.76) more likely than those without hypertension.

Conclusions: Younger T2DM patients had poorer glycemic and cholesterol control than older patients in Singapore and they should have targeted interventions to achieve "optimal" glycemic and cholesterol control.

Keywords: Glycemia; LDL-cholesterol; Control; Younger; Type 2 diabetes mellitus

\section{Introduction}

In Singapore, the prevalence of diabetes mellitus increased from $8.2 \%$ in 2004 to $11.5 \%$ in 2010 amongst its population aged between 18 and 69 years [1]. The increase in diabetes prevalence was observed across all ages, in both genders and all the major ethnic groups, especially the Malays. The prevalence estimates for 2010 (age-standardised to World Standard Population) from the International Diabetes Federation [2] indicate that Singapore's prevalence is much higher than other Asian countries such as Hong Kong (8.5\%), Taiwan $(7.5 \%)$, South Korea $(5.3 \%)$ and Japan $(5.0 \%)$, and other Western countries such as France (6.7\%), Australia (5.7\%) and the United Kingdom (3.6\%).

Type 2 diabetes mellitus (T2DM) is no longer a disease of middle aged and older individuals [3]. Its prevalence in children and adolescents is on the increase in all countries, whether poor or rich [2]. Epidemiologic and prospective studies have reported significant and continuous associations between $\mathrm{HbA} 1 \mathrm{c}$ level and diabetes-related vascular compli- 
cations [4-9]. Younger adults with early exposure to hyperglycemia are at high risk for end-organ damage [4-8]. As with type 1 diabetes, many children with T2DM risk developing complications at an early age, adding to a significant burden on the family and society. There is growing recognition that T2DM in the young is fast becoming a global public health issue with a potentially serious health outcome [10].

Comprehensive and appropriate management of patients with diabetes should include early screening for complications and optimize control of glucose, blood pressure and cholesterol. Very few studies have reported the relationship of age to glycemic control in patients with T2DM and the focus was largely on middle-aged and elderly patients [11]. Conclusions have been mixed, showing high prevalence of poor control in elderly, better glycemic control in older patients [12], or no effect of age on metabolic control [13]. In 2003, El-Kebbi et al studied the relationship of age to glycemic control in an African American population and showed a high prevalence of obesity and poor glycemic control in young adults compared to older patients [14]. A German study in 2009 also reported that the highest percentage of patients with inadequate glycemic control in the T2DM population is not found among the old but the 45 - 54 and 55 - 64 age groups [15].

To date, there has been little comparison of the glycemic control in young adults and elderly patients especially in the Asian population. The aim of this current study was to investigate the relationship of age to glycemic control in Asian patients with T2DM attending the public-sector primary care clinics in Singapore and identify the factors predicting poor glycemic control.

\section{Patients and Methods}

This is a retrospective study of patients attending the National Healthcare Group Polyclinics (NHGP) for the treatment of diabetes mellitus in 2009. The NHGP is a chain of 9 public sector primary care clinics providing basic comprehensive care for the population in the central and western parts of Singapore. It has an integrated electronic patient medical record which hosts both administrative and clinical information. Medical records of all patients with chronic disease conditions such as diabetes mellitus, hypertension, dyslipidemia, stroke, and coronary heart disease are linked to the enterprise-wide National Healthcare Group (NHG) Disease Management System (CDMS) [16].

\section{Study population}

We selected all the patients with existing diagnosis of T2DM from the NHG CDMS who had at least 2 attendances in the same clinic in 2009. Patients who were newly diagnosed with type 2 diabetes mellitus in 2009 or those with type 1 diabetes mellitus were excluded from the study.

\section{Study parameters and data collection}

All the demographic characteristics, medical diagnosis, clinical parameters and laboratory results were extracted directly from the NHG CDMS. Demographic characteristics included age, gender and ethnic group. Medical conditions were extracted based on ICD-9 CM diagnosis codes for hypertension, dyslipidemia, coronary heart disease, stroke, retinopathy, and peripheral vascular disease. Body Mass Index (BMI) and Glomerular Filtration Rate (GFR) were extracted and classified according to WHO guidelines.

Glycated hemoglobin (HbA1c) was the marker for measuring glycemic control. The HbA1c results in 2009 were obtained and a mean $\mathrm{HbA} 1 \mathrm{c}$ was calculated for every patient. Glycemic control was considered "optimal" if HbA1c was $\leq$ $7.0 \%$, "acceptable" if HbA1c was $7.1-8.0 \%$, and "poor" if HbA1c was above $8.0 \%$. Age was grouped into bands of 10 years for comparison of glycemic control.

Two other intermediate outcome measures were also profiled with age bands. The latest blood pressure (both systolic, SBP, and diastolic blood pressure, DBP) and LDL-cholesterol (LDL-c) levels in 2009 were recorded. BP control was considered "optimal" if SBP was $\leq 130 \mathrm{mmHg}$ and DBP was $\leq 80 \mathrm{mmHg}$, "acceptable" if SBP was $131-139 \mathrm{mmHg}$ and DBP was $81-89 \mathrm{mmHg}$, and "poor" if SBP was $\geq 140$ $\mathrm{mmHg}$ and DBP was $\geq 90 \mathrm{mmHg}$. Dyslipidemia control was considered "optimal" if LDL-c was $<2.6 \mathrm{mmol} / \mathrm{L}$, "acceptable" if LDL-c was $2.6-3.3 \mathrm{mmol} / \mathrm{L}$ and "poor" if LDL-c was $\geq 3.4 \mathrm{mmol} / \mathrm{L}$.

\section{Data analysis}

Data was analyzed using PASW (version 18.0). Significance testing of proportions was carried out using Chi-square test, and of means using analysis of variance (ANOVA), where a probability $(\mathrm{P})$ of less than 0.05 was considered significant. Multivariate logistic regression was used to study the factors predicting "poor" glycemic control.

This study was approved by the NHG Domain Specific Review Board.

\section{Results}

There were 58,057 patients with T2DM from 9 primary care clinics in the study. Table 1 shows that females outnumbered males by $54 \%$ : $46 \%$. There were more males than females in the younger age groups up to 54 years and the reverse was observed from 55 years and above. Age is normally distributed (mean $64.0 \pm 11.6$ years), with $64 \%$ aged 60 years and older. Overall, the disproportionately higher proportion of Indians (13\%) in relation to the general Singapore popu- 


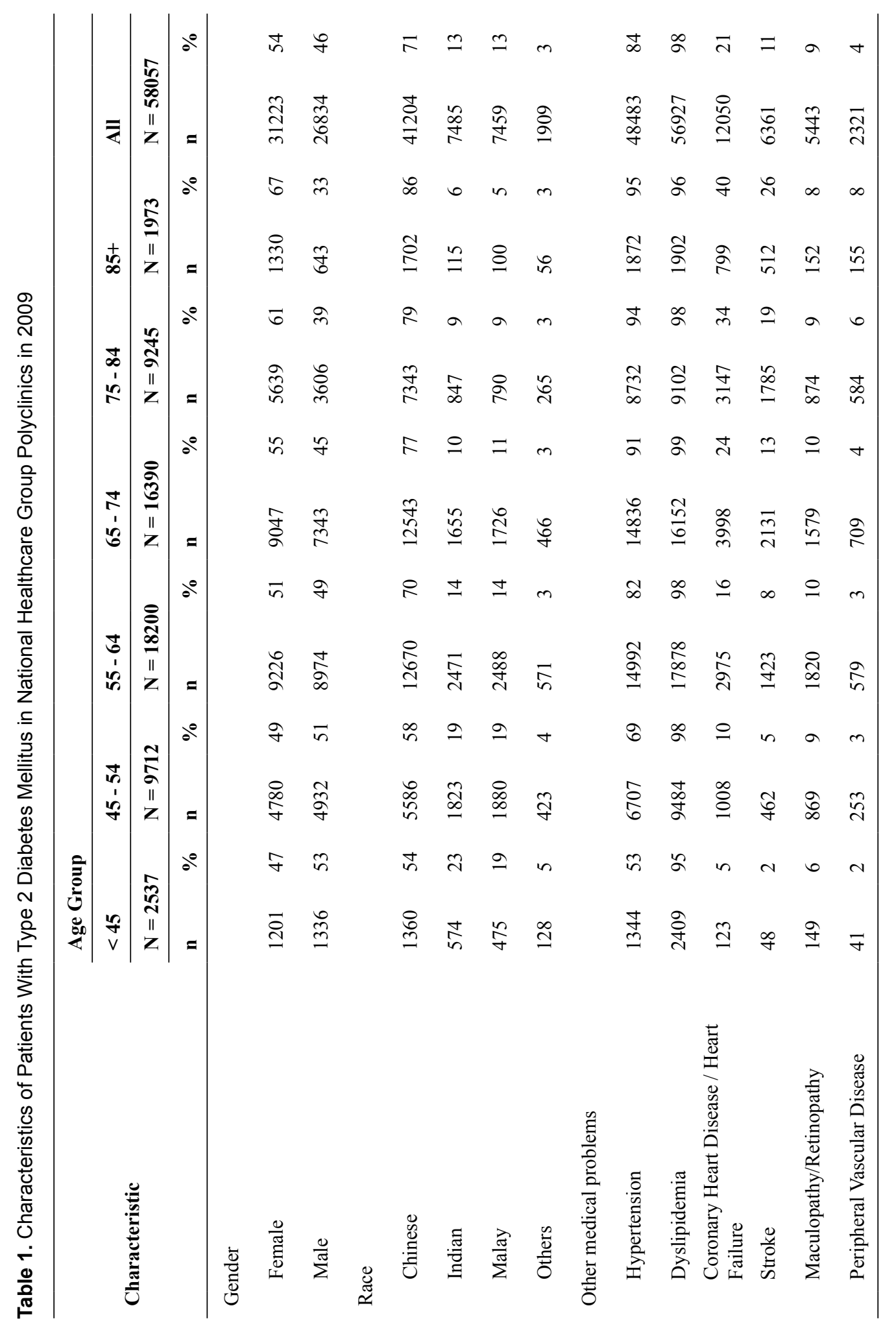




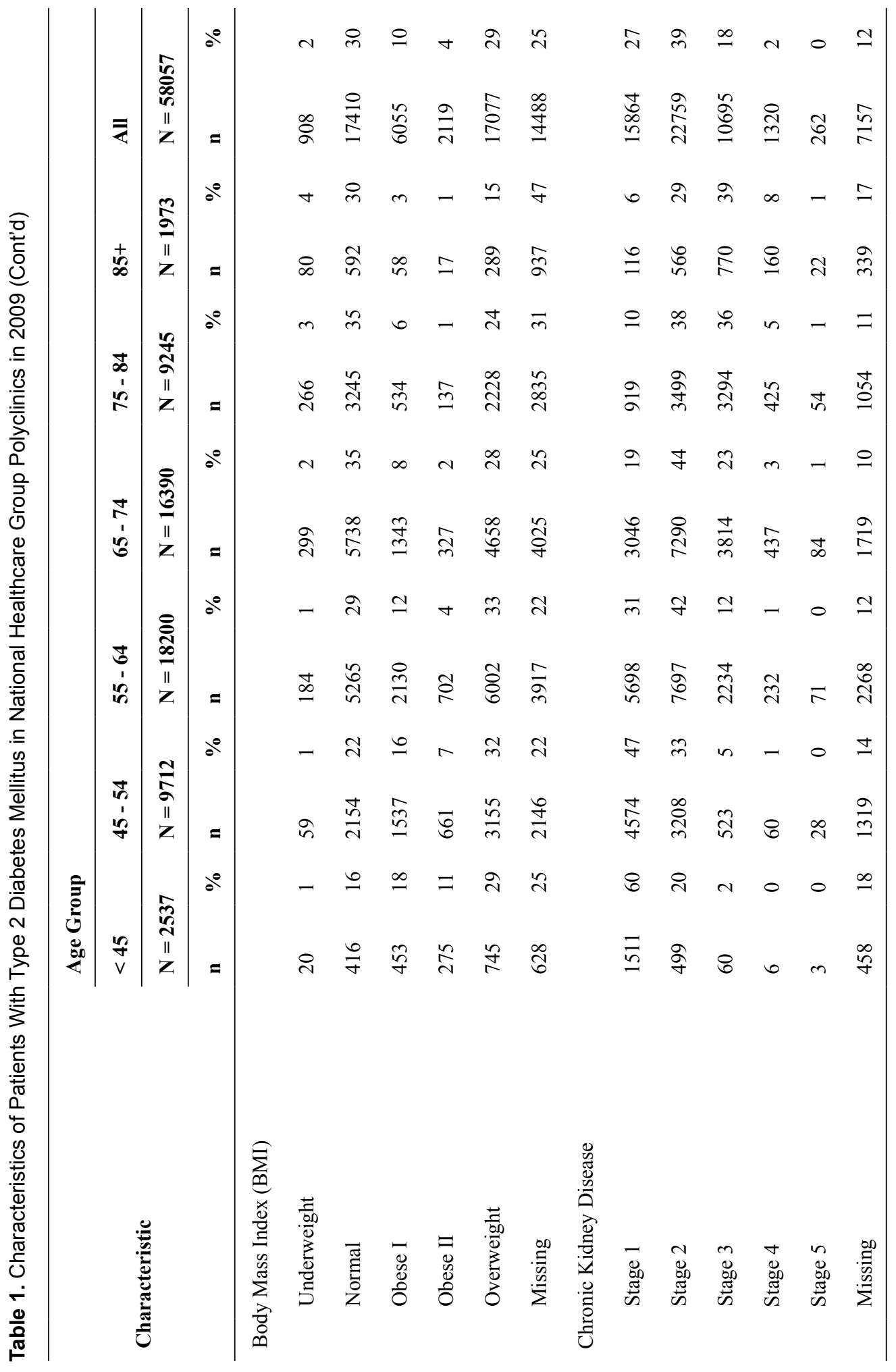




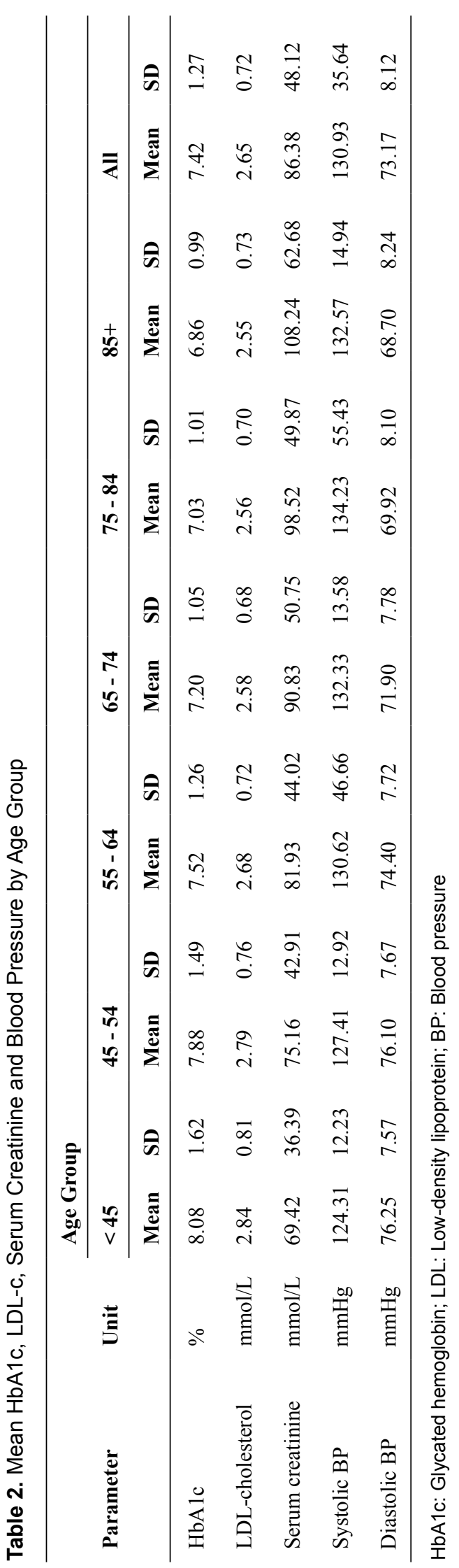

lation reflected the higher incidence of diabetes mellitus in this ethnic group. The Indians and Malays made up 23\% and $19 \%$ respectively among those below 45 years old, declining to below $10 \%$ for patients 75 years and above.

\section{Other medical conditions}

The prevalence of hypertension and dyslipidemia among these T2DM patients were $84 \%$ and $98 \%$ respectively. The prevalence of hypertension increased with age from 53\% (below 45 years) to above 90\% (65 years and above). The prevalence of dyslipidemia was high for all age groups, ranging from $95 \%$ to $99 \%$.

The prevalence of vascular disease conditions increased with age. About 1 in 4 patients were also treated for coronary heart disease (range $5 \%$ to $40 \%$ ), $11 \%$ had history of a cerebrovascular event (range $2 \%$ to $26 \%$ ), $9 \%$ had retinopathy (range $6 \%$ to $10 \%$ ) and $4 \%$ had peripheral vascular disease ( $2 \%$ to $8 \%$ ). The proportion of patients with Chronic Kidney Disease (CKD) stages 1 and 2 decreased with age (Table 1).

\section{BMI distribution}

Mean BMI was $26.3 \pm 4.7 \mathrm{~kg} / \mathrm{m}^{2}$. There were more patients being overweight or obese among the younger age groups compared to older age groups (Table 1). About $1 \%$ to $4 \%$ was underweight, with increasing prevalence among the old age groups. A larger proportion of the older patients, especially those 85 years and older, did not have a weight measurement within the year.

\section{Glycemic control}

Mean $\mathrm{HbA1c}$ decreased with age, from $8.08 \pm 1.62 \%$ for those below 45 years to less than $7 \%$ for those 85 years and above (Table 2). The distribution of HbAlc across the age groups is shown in Figure 1. The proportion of patients in each age group with $\mathrm{HbA} 1 \mathrm{c}>8 \%$ reduced with age, from $40 \%$ (below 45 years) to $10 \%$ ( 85 years and above).

\section{Blood pressure control}

The mean blood pressure was $131 / 73 \mathrm{mmHg}$ (Table 2). When comparing across the age groups, the proportion with "normal" and "high normal" blood pressure control reduced with age from $71.2 \%$ (below 45 years) to $55 \%$ ( 85 years and older).

\section{LDL-cholesterol (LDL-c) control}

Similar to HbA1c, the mean LDL-c decreased with age, from $2.84 \pm 0.81 \mathrm{mmol} / \mathrm{L}$ (below 45 years) to $2.55 \pm 0.73 \mathrm{mmol} / \mathrm{L}$ ( 85 years and older). Proportion with "optimal" LDL-c control increased from $42 \%$ (below 45 years) to $57 \%$ ( 85 years 


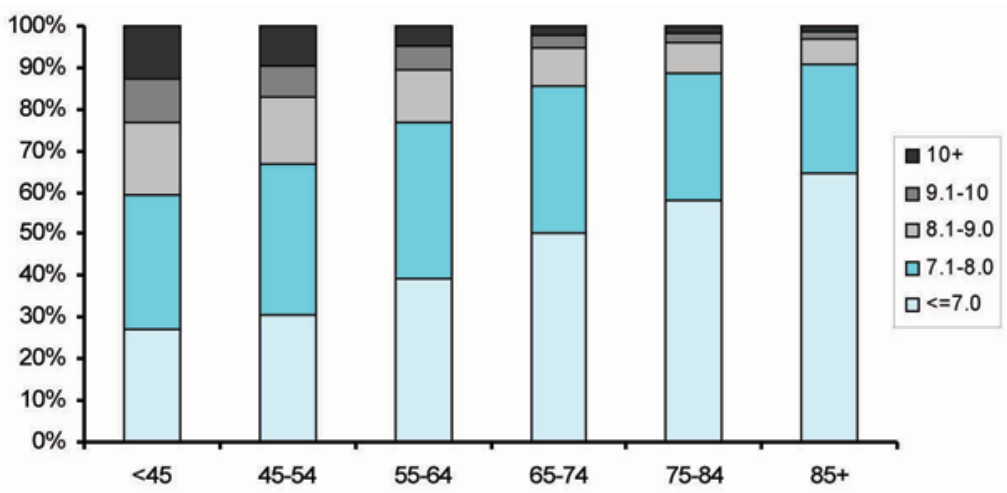

Figure 1. Distribution of mean $\mathrm{HbA} 1 \mathrm{c}(\%)$ by age group.

and above) (Fig. 2).

\section{Management of diabetes mellitus}

The average number of physician clinic visits per year for diabetes care increased with $\mathrm{HbAlc}$ level, from 4.1 (for patients with $\mathrm{HbAlc}$ below 7\%) to 5.2 (for patients with HbAlc $9-10 \%$ ) and 4.9 (for patients with HbA1c above $10 \%$ ). The proportion of patients who visited a Care Manager at least once in the year also increased with $\mathrm{HbAlc}$, from $6.8 \%$ (HbA1c below 7\%) to $52 \%$ (HbAlc above 9\%). Similarly, percentage of patients with visits to the Dietitian increased from $1.3 \%$ (HbAlc below $7 \%$ ) to $10 \%$ (HbAlc above $9 \%$ ).

The proportion of patients in each age group treated with insulin ranged from $6.2 \%$ to $15.4 \%$ and was associated with the degree of glycemic control, increasing from $30.3 \%$ (for patients with mean $\mathrm{HbA} 1 \mathrm{c} 8.1$ to $9.0 \%$ ) to $45.5 \%$ (for patients with mean $\mathrm{HbA1c}$ above $10 \%$ ).

\section{Multivariate logistic regression analysis}

Table 3 shows the results of the multivariate logistic regres- sion to predict "poor" HbA1c level above $8 \%$. Compared to the group 85 years and above, those below 75 years old were significantly more likely to have "poor" HbAlc control. The adjusted OR for $<45$ years was the highest $(4.21 ; 95 \% \mathrm{CI}$ : 3.38 - 5.26), followed by 45 - 54 years $(3.24$; $95 \%$ CI: 2.64 - 3.97), 55 - 64 years $(2.12$; 95\% CI: 1.74 - 2.59) and 65 74 years $(1.31 ; 95 \% \mathrm{CI}: 1.07-1.59)$. Male patients had an adjusted OR 1.21 (95\% CI: 1.15 - 1.27) over the female patients. The Malay and Indian groups had significantly poorer glycemic control compared to the Chinese, with adjusted OR of 1.65 (95\% CI: 1.54 - 1.77) and 1.50 (95\% CI: 1.40 - 1.61) respectively.

Patients with known cardiovascular complications had higher odds of "poor" glycemic control than those without maculopathy or retinopathy, peripheral vascular disease, coronary heart disease or heart failure (Table 3). Patients who were treated with insulin were 8.19 (95\% CI: 7.70 - 8.73) times the odds for having "poor" glycemic control than those on oral hypoglycemic agents only. Those with "poor" glycemic control also had correspondingly poorer LDL-c and blood pressure control. Compared to patients with "optimal" LDL-c $<2.6 \mathrm{mmol} / \mathrm{L}$, the adjusted OR for "poor" glycemic control increased with poorer LDL-c control, from 1.42

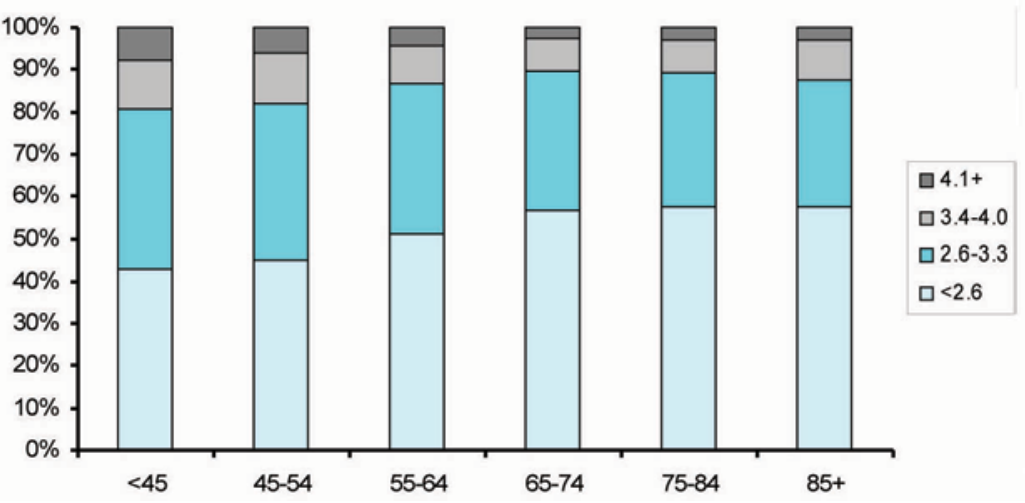

Figure 2. Distribution of mean LDL-cholesterol (mmol/L) by age group. 
Table 3. Logistic Regression for Factors Significantly* Associated With "Poor" Glycemic Control

\begin{tabular}{|c|c|c|c|c|}
\hline \multirow{2}{*}{ Variable } & \multicolumn{4}{|c|}{ "Poor" glycemic control (HbA1c > 8\%) } \\
\hline & Unadjusted OR & $95 \% \mathrm{CI}$ & Adjusted OR & $95 \% \mathrm{CI}$ \\
\hline \multicolumn{5}{|l|}{ Age, y } \\
\hline$<45$ & $6.67^{*}$ & $5.61-7.94$ & $4.21^{*}$ & $3.38-5.26$ \\
\hline $45-54$ & $4.88^{*}$ & $4.16-5.73$ & $3.24^{*}$ & $2.64-3.97$ \\
\hline $55-64$ & $2.99^{*}$ & $2.55-3.50$ & $2.12^{*}$ & $1.74-2.59$ \\
\hline $65-74$ & $1.65^{*}$ & $1.41-1.94$ & $1.31^{*}$ & $1.07-1.59$ \\
\hline $75-84$ & $1.28^{*}$ & $1.08-1.51$ & 1.12 & $0.91-1.37$ \\
\hline$\left[85^{+}\right]$ & 1 & & 1 & \\
\hline \multicolumn{5}{|l|}{ Gender } \\
\hline Male & $1.14^{*}$ & $1.09-1.20$ & $1.21^{*}$ & $1.15-1.27$ \\
\hline [Female] & 1 & & 1 & \\
\hline \multicolumn{5}{|l|}{ Race } \\
\hline [Chinese] & 1 & & 1 & \\
\hline Malay & $2.12^{*}$ & $2.01-2.24$ & $1.65^{*}$ & $1.54-1.77$ \\
\hline Indian & $2.05^{*}$ & $1.94-2.17$ & $1.50^{*}$ & $1.40-1.61$ \\
\hline Others & $1.59^{*}$ & $1.43-1.77$ & $1.31^{*}$ & $1.15-1.49$ \\
\hline \multicolumn{5}{|l|}{ Other Medical Conditions } \\
\hline Maculopathy/Retinopathy (Yes) & $2.14^{*}$ & $2.01-2.27$ & $1.47^{*}$ & $1.36-1.59$ \\
\hline$[\mathrm{No}]$ & 1 & & 1 & \\
\hline Peripheral vascular disease (Yes) & $1.77^{*}$ & $1.61-1.93$ & $1.27^{*}$ & $1.12-1.43$ \\
\hline$[\mathrm{No}]$ & 1 & & 1 & \\
\hline Coronary heart disease (Yes) & 0.99 & $0.95-1.05$ & $1.15^{*}$ & $1.08-1.23$ \\
\hline$[\mathrm{No}]$ & 1 & & 1 & \\
\hline Heart failure (Yes) & $1.39^{*}$ & $1.24-1.54$ & $1.46^{*}$ & $1.27-1.68$ \\
\hline$[\mathrm{No}]$ & 1 & & 1 & \\
\hline Ischemic stroke (Yes) & 0.97 & $0.87-1.10$ & $1.22^{*}$ & $1.06-1.40$ \\
\hline$[\mathrm{No}]$ & 1 & & 1 & \\
\hline \multicolumn{5}{|l|}{ Stage of chronic kidney disease } \\
\hline [Stage 1] & 1 & & 1 & \\
\hline Stage 2 & $0.54^{*}$ & $0.52-0.57$ & $0.63^{*}$ & $0.60-0.67$ \\
\hline Stage 3 & $0.61^{*}$ & $0.57-0.65$ & $0.69^{*}$ & $0.64-0.75$ \\
\hline Stage 4 & 0.99 & $0.87-1.12$ & $0.75^{*}$ & $0.64-0.88$ \\
\hline Stage 5 & 0.81 & $0.60-1.09$ & $0.32 *$ & $0.22-0.47$ \\
\hline
\end{tabular}

[ ] depicts reference group; Adj OR: adjusted odds ratio; Cl: confidence interval; NS: not significant ${ }^{*} \mathrm{P}<0.05$ by stepwise logistic regression analysis 
Table 3. Logistic Regression for Factors Significantly* Associated With "Poor" Glycemic Control (Cont'd)

\begin{tabular}{|c|c|c|c|c|}
\hline \multirow{2}{*}{ Variable } & \multicolumn{4}{|c|}{ "Poor" glycemic control $(\mathrm{HbA} 1 \mathrm{c}>8 \%)$} \\
\hline & Unadjusted OR & $95 \%$ CI & Adjusted OR & $95 \%$ CI \\
\hline \multicolumn{5}{|c|}{ Diabetes Treatment and Control of Risk Factors } \\
\hline Insulin (Yes) & $8.09 *$ & $7.67-8.53$ & $8.19 *$ & $7.70-8.73$ \\
\hline$[\mathrm{No}]$ & 1 & & 1 & \\
\hline \multicolumn{5}{|l|}{ LDL-c control, mmol/L } \\
\hline$[<2.6]$ & 1 & & 1 & \\
\hline $2.6-3.3$ & $1.33^{*}$ & $1.26-1.39$ & $1.42 *$ & $1.34-1.50$ \\
\hline $3.4-4.0$ & $2.22 *$ & $2.07-2.39$ & $2.42 *$ & $2.24-2.62$ \\
\hline $4.1+$ & $4.20 *$ & $3.83-4.62$ & $4.30 *$ & $3.87-4.78$ \\
\hline \multicolumn{5}{|l|}{ Blood pressure control } \\
\hline [Normal] & 1 & & 1 & \\
\hline High Normal & 1.06 & $1.00-1.11$ & $1.10^{*}$ & $1.04-1.17$ \\
\hline Grade 1 Hypertension & 1.06 & $1.00-1.13$ & $1.20^{*}$ & $1.12-1.70$ \\
\hline Grade 2 Hypertension & $1.27 *$ & $1.13-1.43$ & $1.47^{*}$ & $1.27-1.70$ \\
\hline \multicolumn{5}{|l|}{ Body Mass Index (BMI) } \\
\hline Underweight & $0.80 *$ & $0.66-0.95$ & 1.24 & $0.99-1.54$ \\
\hline [Normal] & 1 & & 1 & \\
\hline Overweight & 1.26 & $1.19-1.32$ & $1.31^{*}$ & $1.15-1.49$ \\
\hline Obese Class 1 & $1.63 *$ & $1.52-1.74$ & $1.29 *$ & $1.20-1.39$ \\
\hline Obese Class 2 & $1.94 *$ & $1.75-2.14$ & $1.39 *$ & $1.27-1.53$ \\
\hline
\end{tabular}

[ ] depicts reference group; Adj OR: adjusted odds ratio; Cl: confidence interval; * $\mathrm{P}<0.05$ by stepwise logistic regression analysis

(1.34 - 1.50) for group with LDL-c 2.6 - $3.3 \mathrm{mmol} / \mathrm{L}$ to 4.30 (3.87 - 4.78) for the group with LDL-c above $4.1 \mathrm{mmol} / \mathrm{L}$. Similarly, compared to those with normal blood pressure, adjusted OR for "poor" glycemic control among grade 1 hypertension was $1.20(1.12-1.70)$ and grade 2 hypertension was $1.47(1.27-1.70)$.

\section{Discussion}

A few studies described the relationship of age to glycemic control in patients with diabetes $[12,13,17]$. In the Strong Heart Study among native Americans, age was found to be inversely related to HbAlc level [12]. There was no change in the median HbA1c level at baseline (1989 - 1992) and follow-up (1994 - 1995) surveys. The NHANES III (1988 1994) also reported that younger patients were more likely to have an elevated $\mathrm{HbA} 1 \mathrm{c}$ level, although there was no significant association between age and $\mathrm{HbA} 1 \mathrm{c}$ levels in a predom- inantly white population [13]. In an Australian study, Bruce et al also reported that age was inversely associated with glycemic control whereas duration of diabetes and treatment with either oral hypoglycemic agents or insulin were positively associated with glycemic control [18]. It was noted that octogenarians in Australia differed significantly from younger age groups, those with longer diabetes duration did not demonstrate the increase in hyperglycemia seen in other age groups. A significantly greater proportion of the oldest diabetic subjects had satisfactory HbAlc levels compared with younger subjects.

The Diabcare-Asia project from Singapore, India and Taiwan had earlier reported that one-third to one-half of the diabetic population had poor glycemic control and suboptimal lipid control [19-21]. Our study also supports that, in a predominantly Asian patient population attending primary care clinics, the younger patients had poorer HbAlc and LDL-c control than older patients. The prevalence of hypertension and dyslipidemia were high across all ages and 
higher than the prevalence in the general population. As expected, the prevalence of vascular complications such as coronary heart disease and cerebrovascular disease increased with age and were higher than the general population without diabetes mellitus [22-25].

Studies have suggested that early onset T2DM was associated with an increased risk for complications compared with later onset diabetes [26] and that the development and progression of complications might be more rapid in early onset disease [27-29]. Song et al in 2009 reported that the management of risk factors for diabetes complications was inadequate among the early onset T2DM cohort and they were at substantial risk of developing diabetes complications in later years and at an earlier stage [30]. Our study also showed that the poor glycemic control among the younger T2DM patients was associated with poorer cholesterol and blood pressure control. These younger patients have a higher lifetime risk of developing micro- and macro-vascular complications and should be treated much more aggressively to achieve "optimal" glycemic, blood pressure and cholesterol control [7, 9, 22, 31-36].

It is not fully understood why younger patients have worse glycemic control than older patients. In Singapore, all citizens regardless of age have equal access to medical care provided by the public sector. The older patients may be more motivated to take care of their diabetes and are more compliant with their medication and eat healthy lowfat diet [37]. On the other hand, younger patients might be more likely to disregard diabetes as being important and be less adherent to medication, lifestyle and diet restrictions. Similar findings were reported by El-Kebbi in 2003 that the persistence of HbA1c elevation in younger individuals could be due to inadequately low medication dosage or infrequent use of combination drug regimens [14]. The younger patient also tends to be more obese than older patients with resultant higher insulin resistance and may need more aggressive therapy to achieve glycemic control. In addition to treating raised $\mathrm{HbAlc}$, physicians should be alerted to commence or reinforce aggressive lifestyle intervention, lipid-lowering and anti-hypertensive therapy especially for the younger T2DM patients.

This study also showed that patients with "optimal" glycemic control had fewer visits to the clinic annually for the treatment of diabetes. Those with "poor" glycemic control were more likely to have visited a Care Manager and Dietitian for general self-management tips, health information and dietary advice on diabetes. The overall healthcare utilization and expenditure would be correspondingly higher for patients with poorer glycemic control. Wagner showed that a sustained reduction in $\mathrm{HbA}$ 1c level among adult diabetic patients is associated with significant cost savings within 1 to 2 years of improvement [38].

There are several limitations in this study. As data was drawn from the Diabetes Registry, we were unable to collect data to adjust for the duration of diabetes mellitus which may be associated with progressive impairment of insulin secretion. There was also no data on physical activity and adherence of diet and lifestyle. Some patients, especially the older ones, did not have BMI measurement.

Nonetheless, this study of an Asian population with diabetes mellitus has provided an insight into the variation of glycemic and cholesterol control with age. We analyzed the data of a large captive population from the Diabetes Registry and we were able to study the prevalence of hypertension, dyslipidemia and other vascular complications in patients with T2DM. All laboratory results were captured directly and were accurate and complete. The mean HbAlc for the year was calculated for every patient to reflect the average glycemic control over a year instead of using a single HbAlc reading.

Younger diabetics are at higher cumulative risk to develop vascular-related complications over time. The reasons for poor glycemic and cholesterol control are not well understood and are likely to be multifactoral. Future research could study patient's health literacy and their understanding of diabetes, health-seeking and treatment-adherence behavior across the ages.

This study shows that younger patients with T2DM had poorer glycemic and cholesterol control than older patients in Singapore. Those with poor glycemic control also had corresponding poorer cholesterol and blood pressure control. These patients had a higher lifetime risk of developing micro- and macro-vascular complications and more research should be done to investigate reasons for the poorer control so that targeted interventions can be designed for them.

\section{Acknowledgments}

We would like to thank the patients and clinicians at NHG Polyclinics for contributing data for this study and members of the NHG Diabetes Disease Management Workgroup for their contribution to the CDMS and study. We would also like to thank Mr. Fong Chee Weng from the Epidemiology \& Disease Control Division of Ministry of Health in Singapore for providing information on the National Health Survey results.

\section{Financial Disclosure}

The authors declare that they have no relevant financial interests in this manuscript.

\section{References}

1. www.channelnewsasia.com/stories/singaporelocalnews/ 
view/1095709/1/.html of 26 Nov 20101632 hrs.

2. Diabetes Atlas Committee. Diabetes Atlas. 3rd ed. Brussels (Belgium): International Diabetes Federation, 2006.

3. Zimmet PZ, McCarty DJ, de Courten MP. The global epidemiology of non-insulin-dependent diabetes mellitus and the metabolic syndrome. J Diabetes Complications 1997;11(2):60-68.

4. Klein R. Hyperglycemia and microvascular and macrovascular disease in diabetes. Diabetes Care 1995;18(2):258-268.

5. Kuusisto J, Mykkanen L, Pyorala K, Laakso M. NIDDM and its metabolic control predict coronary heart disease in elderly subjects. Diabetes 1994;43(8):960-967.

6 . The effect of intensive treatment of diabetes on the development and progression of long-term complications in insulin-dependent diabetes mellitus. The Diabetes Control and Complications Trial Research Group. N Engl J Med 1993;329(14):977-986.

7. Intensive blood-glucose control with sulphonylureas or insulin compared with conventional treatment and risk of complications in patients with type 2 diabetes (UKPDS 33). UK Prospective Diabetes Study (UKPDS) Group. Lancet 1998;352(9131):837-853.

8. Ohkubo Y, Kishikawa H, Araki E, Miyata T, Isami S, Motoyoshi S, Kojima Y, et al. Intensive insulin therapy prevents the progression of diabetic microvascular complications in Japanese patients with non-insulin-dependent diabetes mellitus: a randomized prospective 6-year study. Diabetes Res Clin Pract 1995;28(2):103-117.

9. Elley CR, Kenealy T, Robinson E, Drury PL. Glycated haemoglobin and cardiovascular outcomes in people with Type 2 diabetes: a large prospective cohort study. Diabet Med 2008;25(11):1295-1301.

10. Fagot-Campagna A, Narayan KM, Imperatore G. Type 2 diabetes in children. BMJ 2001;322(7283):377-378.

11. Smith NL, Heckbert SR, Bittner VA, Savage PJ, Barzilay JI, Dobs AS, Psaty BM. Antidiabetic treatment trends in a cohort of elderly people with diabetes. The cardiovascular health study, 1989-1997. Diabetes Care 1999;22(5):736-742.

12. Hu D, Henderson JA, Welty TK, Lee ET, Jablonski KA, Magee MF, Robbins DC, et al. Glycemic control in diabetic American Indians. Longitudinal data from the Strong Heart Study. Diabetes Care 1999;22(11):18021807.

13. Shorr RI, Franse LV, Resnick HE, Di Bari M, Johnson KC, Pahor M. Glycemic control of older adults with type 2 diabetes: findings from the Third National Health and Nutrition Examination Survey, 1988-1994. J Am Geriatr Soc 2000;48(3):264-267.

14. El-Kebbi IM, Cook CB, Ziemer DC, Miller CD, Gallina DL, Phillips LS. Association of younger age with poor glycemic control and obesity in urban african americans with type 2 diabetes. Arch Intern Med 2003;163(1):69-
75.

15. Huppertz E, Pieper L, Klotsche J, Stridde E, Pittrow D, Bohler S, Lehnert H. Diabetes Mellitus in German Primary Care: quality of glycaemic control and subpopulations not well controlled - results of the DETECT study. Exp Clin Endocrinol Diabetes 2009;117(1):6-14.

16. Toh MP, Leong HS, Lim BK. Development of a diabetes registry to improve quality of care in the National Healthcare Group in Singapore. Ann Acad Med Singapore 2009;38(6):546-551.

17. Carter JS, Gilliland SS, Perez GE, Skipper B, Gilliland FD. Public health and clinical implications of high hemoglobin A1c levels and weight in younger adult Native American people with diabetes. Arch Intern Med 2000;160(22):3471-3476.

18. Bruce DG, Davis WA, Davis TM. Glycemic control in older subjects with type 2 diabetes mellitus in the Fremantle Diabetes Study. J Am Geriatr Soc 2000;48(11):1449-1453.

19. Lee WR, Lim HS, Thai AC, Chew WL, Emmanuel S, Goh LG, Lau HC, et al. A window on the current status of diabetes mellitus in Singapore--the Diabcare-Singapore 1998 study. Singapore Med J 2001;42(11):501-507.

20. Raheja BS, Kapur A, Bhoraskar A, Sathe SR, Jorgensen LN, Moorthi SR, Pendsey S, et al. DiabCare Asia--India Study: diabetes care in India--current status. J Assoc Physicians India 2001;49:717-722.

21. Chuang LM, Tsai ST, Huang BY, Tai TY. The status of diabetes control in Asia--a cross-sectional survey of 24 317 patients with diabetes mellitus in 1998. Diabet Med 2002;19(12):978-985.

22. Preis SR, Pencina MJ, Hwang SJ, D’Agostino RB, Sr., Savage PJ, Levy D, Fox CS. Trends in cardiovascular disease risk factors in individuals with and without diabetes mellitus in the Framingham Heart Study. Circulation 2009;120(3):212-220.

23. Fox CS, Coady S, Sorlie PD, Levy D, Meigs JB, D'Agostino RB, Sr., Wilson PW, et al. Trends in cardiovascular complications of diabetes. JAMA 2004;292(20):2495-2499.

24. Fox CS, Coady S, Sorlie PD, D'Agostino RB, Sr., Pencina MJ, Vasan RS, Meigs JB, et al. Increasing cardiovascular disease burden due to diabetes mellitus: the Framingham Heart Study. Circulation 2007;115(12):1544-1550.

25. Selvin E, Coresh J, Golden SH, Brancati FL, Folsom AR, Steffes MW. Glycemic control and coronary heart disease risk in persons with and without diabetes: the atherosclerosis risk in communities study. Arch Intern Med 2005;165(16):1910-1916.

26. Hillier TA, Pedula KL. Complications in young adults with early-onset type 2 diabetes: losing the relative protection of youth. Diabetes Care 2003;26(11):2999-3005.

27. Pinhas-Hamiel O, Zeitler P. Acute and chronic complications of type 2 diabetes mellitus in children and ado- 
lescents. Lancet 2007;369(9575):1823-1831.

28. Pavkov ME, Bennett PH, Knowler WC, Krakoff J, Sievers ML, Nelson RG. Effect of youth-onset type 2 diabetes mellitus on incidence of end-stage renal disease and mortality in young and middle-aged Pima Indians. JAMA 2006;296(4):421-426.

29. Chuang LM, Soegondo S, Soewondo P, Young-Seol K, Mohamed M, Dalisay E, Go R, et al. Comparisons of the outcomes on control, type of management and complications status in early onset and late onset type 2 diabetes in Asia. Diabetes Res Clin Pract 2006;71(2):146-155.

30. Song SH, Hardisty CA. Early onset type 2 diabetes mellitus: a harbinger for complications in later years-clinical observation from a secondary care cohort. QJM 2009;102(11):799-806.

31. Tight blood pressure control and risk of macrovascular and microvascular complications in type 2 diabetes: UKPDS 38. UK Prospective Diabetes Study Group. BMJ 1998;317(7160):703-713.

32. Shepherd J, Barter P, Carmena R, Deedwania P, Fruchart JC, Haffner S, Hsia J, et al. Effect of lowering LDL cholesterol substantially below currently recommended levels in patients with coronary heart disease and diabetes: the Treating to New Targets (TNT) study. Diabetes Care 2006;29(6):1220-1226.

33. Hansson L, Zanchetti A, Carruthers SG, Dahlof B, Elm- feldt D, Julius S, Menard J, et al. Effects of intensive blood-pressure lowering and low-dose aspirin in patients with hypertension: principal results of the Hypertension Optimal Treatment (HOT) randomised trial. HOT Study Group. Lancet 1998;351(9118):1755-1762.

34. Collins R, Armitage J, Parish S, Sleigh P, Peto R. MRC/ BHF Heart Protection Study of cholesterol-lowering with simvastatin in 5963 people with diabetes: a randomised placebo-controlled trial. Lancet 2003;361(9374):20052016.

35. Gerstein HC, Miller ME, Byington RP, Goff DC, Jr., Bigger JT, Buse JB, Cushman WC, et al. Effects of intensive glucose lowering in type 2 diabetes. $\mathrm{N}$ Engl $\mathrm{J}$ Med 2008;358(24):2545-2559.

36. Patel A, MacMahon S, Chalmers J, Neal B, Billot L, Woodward M, Marre M, et al. Intensive blood glucose control and vascular outcomes in patients with type 2 diabetes. N Engl J Med 2008;358(24):2560-2572.

37. Glasgow RE, Hampson SE, Strycker LA, Ruggiero L. Personal-model beliefs and social-environmental barriers related to diabetes self-management. Diabetes Care 1997;20(4):556-561.

38. Wagner EH, Sandhu N, Newton KM, McCulloch DK, Ramsey SD, Grothaus LC. Effect of improved glycemic control on health care costs and utilization. JAMA 2001;285(2):182-189. 